\title{
A Drosophila SH2-SH3 Adaptor Protein Implicated in Coupling the Sevenless Tyrosine Kinase to an Activator of Ras Guanine Nucleotide Exchange, Sos
}

\author{
Jean Paul Olivier, ${ }^{*} \dagger$ Thomas Raabe, $\ddagger$ \\ Mark Henkerneyer, ${ }^{*}$ Barry Dickson, $\ddagger$ \\ Geraldine Mbamalu, ${ }^{*}$ Ben Margolis, $\S$ \\ Joseph Schlessinger, § Ernst Hafen, $\ddagger$ \\ and Tony Pawson*† \\ *Division of Molecular and Developmental Biology \\ Samuel Lunenfeld Research Institute \\ Mount Sinai Hospital \\ Toronto, Ontario M5G 1x5 \\ Canada \\ †Department of Molecular and Medical Genetics \\ University of Toronto \\ Toronto. Ontario M5S 1 A8 \\ Canada \\ ‡Zoologisches Institut \\ Universitat Zurich \\ Winterhurerstrasse 190 \\ $\mathrm{CH}-8057$ Zurich \\ Switzerland \\ §Department of Pharmacology \\ Kaplan Cancer Center \\ New York University Medical Center \\ New York, New York 10016
}

\section{Summary}

A Drosophila gene (drk) encodes a widely expressed protein with a single $\mathrm{SH} 2$ domain and two flanking SH3 domains, which is homologous to the Sem-5 protein of $C$. elegans and mammalian GRB2. Genetic analysis suggests that drk function is essential for signaling by the sevenless receptor tyrosine kinase. Drk biological activity correlates with binding of its $\mathrm{SH} 2$ domain to activated receptor tyrosine kinases and concomitant localization of drk to the plasma membrane. In vitro, drk also binds directly to the C-terminal tail of Sos, a Ras guanine nucleotide-releasing protein (GNRP), which, like Rasl and drk, is required for sevenless signaling. These results suggest that drk binds autophosphorylated receptor tyrosine kinases with its $\mathrm{SH} 2$ domain and the Sos GNRP through its Ski3 domains, thereby coupling receptor tyrosine kinases to Ras activation. The conservation of these signaling proteins during evolution indicates that this is a general mechanism for linking tyrosine kinases to Ras.

\section{Introduction}

Growth factor receptors with protein-tyrosins kinase activity mediate the biological effects of many of the polypeptide hormones that control cell proliferation, differentiation, and metabolism (Ullrich and Schlessinger, 1990; Pawson and Bernstein, 1990; Cantley et al., 1991). Cytoptasmic Src-like tyrosine kinases are also implicated in signal transduction processes, for example during $\mathrm{T}$ cell activation (Stein et al., 1992; Appleby et at., 1992; Strauss and Weiss, 1992; Abraham et al., 1992). Furthermore, a number of cellular and viral oncogenes encode constitutively active variants of tyrosine kinases, which contribute to the development oi specific cancers (Konopka et al., 1984; Hunter and Cooper, 1985). A principal intracellular signaling pathway by which tyrosine kinases stimulate cell growth and differentiation involves the activation of Ras guanine nucleotide-binding proteins, by conversion of Ras from a GDP- to a GTP-bound state. The notion that Ras might be important in propagating signals downstream of tyrosine kinases was originally suggested by the effects of microinjecting anti-Ras antibody into mammalian fibroblasts. Neutralizing antibody to Ras blocks the ability of both normal growth factor receptors and oncogenic tyrosine kinases to induce DNA synthesis (Mulcahy et al., 1985; Smith et al., 1986). Similarly, anti-Ras antibody and the S17N dominant inhibitory Ras protein Inhibit the capacity of nerve growth factor, acting through the Trk tyrosine kinase, to induce neurite extension in PC12 neuronal cells (Szeberenyi et al., 1990; Hagag et al., 1986). Expression of S17N inhibitory Ras protein in PC12 cells or in fibroblasts also blocks the activation of serinel threonine kinases, such as Raf and MAP kinase, in response to nerve growth factor, platelet-derived growth factor, or insulin (Thomas et al., 1352; Wood et al., 1992; de Vries-Smits et al., 1992). These results indicate that Ras functions downstream of tyrosine kinases in mammalian cells to regulate Raf and tile MAP kinase pathway.

The genetic dissection of signal transduction pathways in Crosophila melanogaster and Caenorhabditis elegans has indicated that receptor tyrosine kinases, as well as Ras and Rai proteins, also play an essential role in cellcell communication during invertebrate development (Greenwald and Rubin, 1992; Horvitz and Sternberg, 1991; Dickson and Hafen, 1992; Dicksonet al., 1992b). In Drosophila, the specification of R7 photoreceptor cells in the developing oninatidial units of the compound eye is dependent on the local activation of the sevenless (sev) receptor tyrosine kinase in the $\mathrm{R} 7$ precursor cell (Hafen et al., 1987). In the absence of functional sev protein, the R7 precursor does not develop into a photoreceptor cell, but rather into a nonneuronal cone cell (Tomlinson and Ready, 1086). Conversely, the constitutive activation of sev kinase activity in the R7 and other ommatidial precursor cells results in the formation of multiple R7 cells in each ommatidium (Basler et al. 1991). The response of ommatidial precursor cells to either a partially functional, or a constitutively active sev kinase is dosage sensitive. This observation has been exploited to identify genetically downstream components of the sev signaling pathway, establishing that Gapl, Ras1, and Son of sevenless (Sos), a putative guanine nucleotide-releasing protein (GNRP), play essential roles in signaling from the sev receptor (Rogge et al., 1992; Gaul et al. 1992; Sinion et al., 1991: Rogge et al., 1991). Similarly, in C. elegans it has been shown that a receptor tyrosine kinase encoded by the let23 gene and a Ras protein encoded by let- 60 are required for inducrion of the vulval cell fate (Aroian et al., 1990; Beitel et al., 1990; Han and Sternberg, 1990).

Ras proteins are biologically inactive in the GDP-bound state and are activated by the exchange of GDP for GTP (Bourne et al., 1991). In principle, Ras GTP binding could be induced either by stimulation of guanine nucleotide 
exchange by a GNRP or by inhibition of a Ras GTPaseactivating protein (GAP). In the sev pathway, it has been proposed that Ras1 activation is achieved both by stimulation of the Sos GNRP arid by inhibition of Gap1 (Rogge et al., 1992; Gaul et al., 1992). Biochemical data from mammalian cells have shown that growth factors increase the fraction of Ras in the GTP-bound state (Gibbs et al., 1990; Satoh et al., 1990a, 1990b), and have suggested that regulation of GNRP activity may be the predominant mechanism by which growth factor receptors control Ras activation (Zhang et al., 1992; Medema et al., 1993). However, nothing is known about the mechanisms by which tyrosine kinases might communicate with a Ras GMRP.

Targets of receptor tyrosine kinases frequently possess Src homology 2 (SH2) domains that bind to specific phosphotyrosine-containing sites on activated receptors (Koch et al., 1991; Pawson and Gish, 1992). Such high affinity interactions appear important for the subsequent stimulation of $\mathrm{SH} 2$-containing cytoplasmic enzymes by tyrosine kinases, leading to the modulation of intracellular signaling pathways (Vega et al., 1992; Peters et al., 1992; Mohammadi et al., 1992). A majority of proteins with $\mathrm{SH} 2$ domains also contain one or more $\mathrm{SH} 3$ domains (Mayer et al., 1988; Musacchio et al., 1992a). While the biological functions of SH3 domains are uncertain, the Abl SH3 domain was recently shown to bind in vitro to a prolinerich sequence within a protein (3BP-1) that also contains a presumptive Rho/Rac GAP domain (Cicchetti et al., 1992). Although polypeptides with $\mathrm{Ski} 2$ and $\mathrm{SH} 3$ domains frequently also possess enzymatic domains, the products of the sem-5iGRB2, crk, and nck genes are composed almost exclusively of $\mathrm{SH} 2$ and $\mathrm{SH} 3$ domains (Clark et al., 1992; Lowenstein et al., 1992; Mayer et al., 1988; Lehmann et al., 1990). These protsins may serve as adaptors, by coupling tyrosine kinases to downstream targets that themselves do not contain $\mathrm{SH} 2$ or $\mathrm{SH} 3$ domains.

Genetic evidence from $\mathrm{C}$. elegans indicates that the sem- 5 gene product, which contains a single $\mathrm{SH} 2$ domain flanked by two $\mathrm{SH} 3$ domains, functions on the same pathway as the Let-23 receotor tyrosine kinase and Let601 Ras during induction of vulva1 differentiation (Clark ei al., 1392). A mammalian homolog of sem-5 has been ,identified, GRB2, suggesting that this pathway has been highly conserved in evolution (Lowenstein et al., 1992). If proteins with $\mathrm{SH} 2$ and $\mathrm{SH} 3$ domains also provide a link between the sev receptor tyrosine kinase and Ras in the R7 pathway, mutations in the corresponding genes might be expected to impair signaling from the receptor, as observed for mutations in Sos and Ras1. Here we describe the identification of a Drosophila homolog of sem-5iGRB2: drk (downstream of receptor kinases). Mutations at the $d r k$ locus have been identified in screens for second site modifiers oi both loss- and gain-of-function sev alleles, implicating drk as an essential component of the sev signal transduction pathway. We present both genetic and bioche-nical evidence suggesting that this protein couples receptor tyrosine kinases through its $\mathrm{SH} 2$ and $\mathrm{SH} 3$ domains to Sos, a Ras GNRP.

\section{Results}

Isolation of a cDNA Encoding a Drosophila Hamolog of sem-5/iGRB2
To identify Drosophiia cDNAs that might encode Ski2 domains, a cDNA expression library made from Drosophila embryos at 10-12 hr of development was screened using the CORT procedure (Skolnik et al., 1991; Margolis et al., 1992). The cDNA expression library was screened with a phosphotyrosine-containing C-terminal fragment of the activated human epidermal growth factor (EGF) receptor, which contains high affinity binding sites for the SH2 domains

of several mammalian signaling proteins (Margolis et al., 1990; Skolnik et al., 1591), including GRB2 (Lowenstein et al., 1992). We considered it possible that this phosphotyrosine-containing EGF receptor fragment would also bind the $\mathrm{SH} 2$ domains of Drosophila signaling proteins.

The cDNA insert of a single positive bacteriophaga was sequenced and proved to encode a polypeptide sequence containing an $\mathrm{SH} 2$ domain. To obtain the complete coding sequence, the library was rescreened using this cDNA as a probe, leading to the isolation of an $1156 \mathrm{bp}$ cDNA containing a single open reading frame. This latter CDNA is predicted to encode a protein of 211 amino acids, with a molecular mass of $24 \mathrm{kd}$ (Figure 1A). Analysis of the drk protein sequence showed that it contains a centrally located $\mathrm{SH} 2$ domain, flanked by two $\mathrm{SH} 3$ domains (Figure 18). The $\mathrm{SH} 2$ sequence possesses residues that are highly conserved among other $\mathrm{SH} 2$ domains (Koch et al., 1991), apparently because they are important for $\mathrm{SH} 2$ structure and function (Waksman et al., 1992; Overduin et al., 1992; Booker et al., 1992). The drk SH3 domains contain characteristic residues (Musacchio et al., 1992a), which from structural analysis of the spectrin and Src SH3 domains are involved in formation of the $\mathrm{SH} 3$ fold or in ligand binding (Yu et al., 1992; Musacchio et al., 1992b). The Drosophila drk polypeptide is most similar in both overail structure and amino acid sequence to the Sem-5 protein of C. elegans (61\% identity) and human GRB2 (63\% identity) (Figure 18). These results suggest that drk is a Drosophila homolog of sem-51GRB2.

\section{Expression of drk RNA and Protein}

To determine the cells in which drk is expressed during development, we performed in situ hybridization with digoxigenin-labeled probes to whole-mount imaginal discs of third instar lahae. As a control we employed a probe to the sev transcript, which is specifically expressed in a subpopulation of developing ommatidial cells behind the morphogenetic fcrrow (Figure 2A). In contrast with sev, we detected a strong, homogeneous labeling of all cells in the $\operatorname{dev}$ \$loping eye and antenna1 disc with the $d r k$ probe (Figure 25). Widespread expression of $d r k$ was also observed in the other imaginal discs tested, as well as in the embryo (data riot shown). It therefore appears that $d r k$ is broadiy expressed in many different cell types.

To identify the drk protein, polyclonal antibodies were raised to the full-length drk polypeptide, synthesized in bacteria using the pET expression system. Affinity-purified anti-drk antibodies specifically recognized a $24 \mathrm{kd}$ protein in Western blots of Drosophila extracts. The $24 \mathrm{kd}$ drk protein was present in similar amounts in lysates from pupae, lame, and adults (Figure 3). These results provide direct evidence that drk encodes a 24 kd polypeptide that is widely expressed throughout the Drosophila life cycle. 


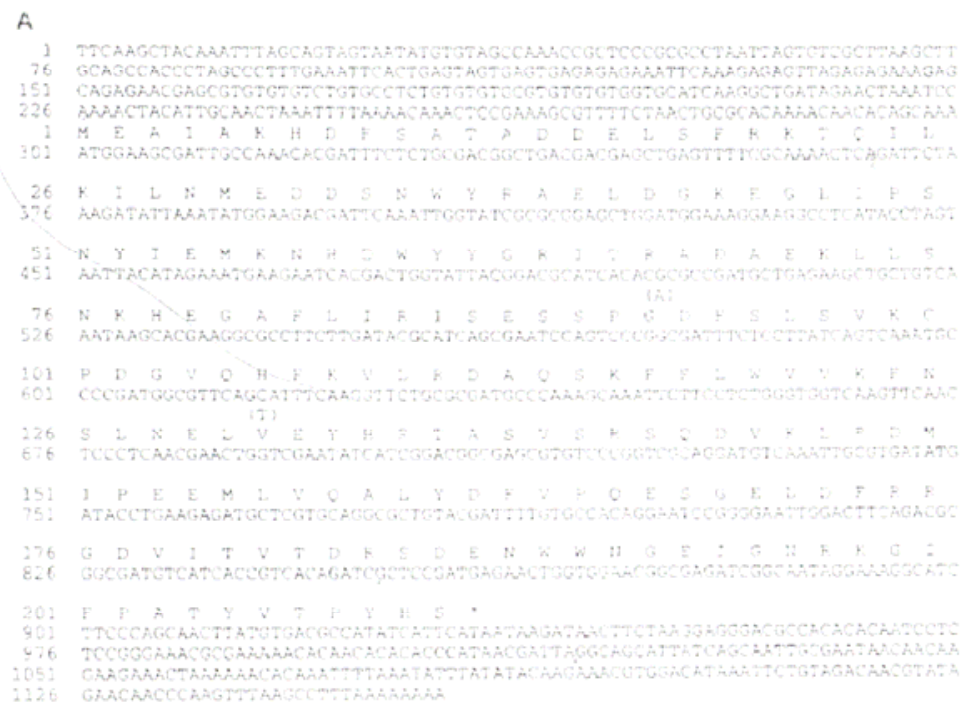

B

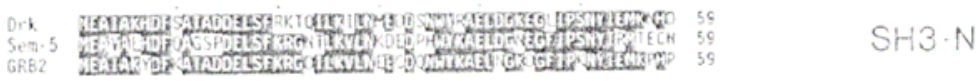

Y

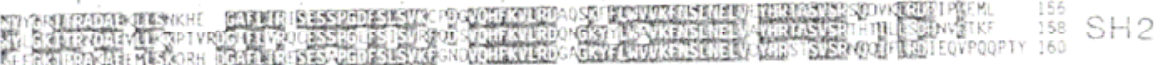

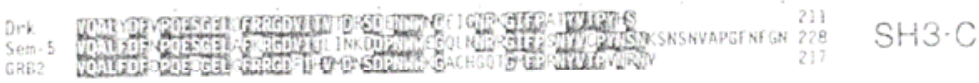

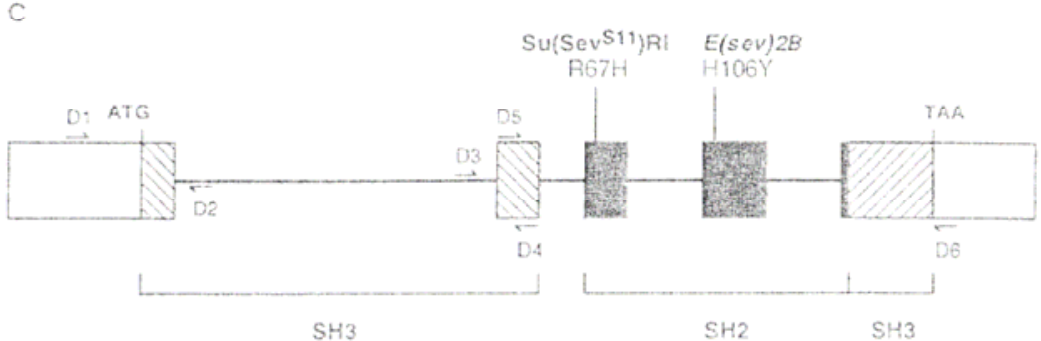

Figure 1. Sequence of Wild-Type and Mutant $d r k$

(A) The nucleotide sequence of the drk cDNA and the predicted amino acid sequence of the drk protein are shown. Mutations In the Su(Sev ${ }^{511}$ )R1 (residue 500 of the cDNA sequence) and $E(\operatorname{sev} 2 B)$ (residue 616 ) alleles are indicated below the main DNA sequence

(B) A comparison of the ark, Sern-5, and GRB2 proteins is shown. The sequence is divided into the N-terminal SH3 domain (SH3-N), the SH2 domain, and the C-terminal SH3 domain (SH3-C). identical residues are highlighted in reverse type. Arrows indicate the amino acids substituted as a consequence of the Su(Sev $\left.{ }^{\mathrm{S}}\right) R 1$ and $E\left(\mathrm{sev}^{2 B}\right)$ mutations. (C) drk genomic structure. Exons are indicated by boxes: exon sequences encoding the SH2 domain are closed, while those encoding either $\mathrm{SH} 3$ domain rehatched. The locations of the condons affected by the Su(Sev $\left.{ }^{S 1}\right) R 1$ and $E(\operatorname{sev} 2 B)$ mutations, and the resulting amino acid substitutions, are shown. The positions of primer sequences, used for PCR amplification of $3 \%$ genomic sequences, are indicated.

\section{Drk Plays an Essential Role in the Sev Signal}

\section{Transduction Cascade}

The cytological map position of the drk gene was determined using in situ hybridization to polytene chromosomes. A single site of hybridization at position $50 \mathrm{~A}$ on the right arm of the second chromosome was detected (data not shown). This physical location corresponds roughly to the site of the mutation $E(\mathrm{sev}) 2 B$, which has been isolated as a dominant enhancer of a weak sev mutation (Simon et al., 1991). In an independent screen for mutations that, in the heterozygous state, suppress the rough eye phenotype associated with the gain-of-function mutation $\mathrm{Sev}^{\text {S11 }}$, we have identified a single ethyl methanesulfonate-induced mutation and six $\mathrm{P}$ element-induced insertions, which upon genetic analysis have.proven to be alleles of $E(s e v) 2 B$. Drosophila heterozygous for the ethyl methanesulfonate-induced allele $\mathrm{Su}\left(\mathrm{Sev}^{\mathrm{S} 11}\right) R 1$ exhibit almost complete suppression of the rough eye phenotype caused by the formation of multiple R7 cells per ommatidium in $\mathrm{Sev}^{\mathrm{S} 11}$ flies (Figures $4 \mathrm{~A}$ and $4 \mathrm{~B}$ ). The six $\mathrm{P}$ element-induced alleles were found to have $P$ element insertions at $50 \mathrm{~A}$, the map position of 


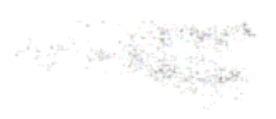

the drk gene. This suggested that the $S u\left(S_{e v}{ }^{S 11}\right) R 1$ and $E(\operatorname{sev}) 2 B$ mutations might lie within the $d r k$ gene.

The $S e v^{S 11}$ phenotype is caused by the overexpression of a truncated, activated sev kinase under the control of a duplicated sev enhancer (sE). We assume that the suppression of the Sev ${ }^{S 11}$ phenotype in flies heterozygous for $\mathrm{Su}\left(\mathrm{Sev}^{\mathrm{S11}}\right) R 1$ is caused by a reduction in the amount of functional $\mathrm{Su}\left(\mathrm{Sev}^{\mathrm{S} 11}\right) R 1$ gene product. If drk is indeed encoded by the $S u\left(S_{e v}{ }^{S 11}\right) R 1$ locus, it should be possible to revert the dominant suppression induced by this mutation by expressing the wild-type drk cDNA under control of the sev enhancer. For this purpose, we assembled a $\mathrm{P}$ element transformation construct, containing the drk cDNA joined to both the $h s p 70$ promoter and the sev enhancer sequences (sE-hsp-drk), linked to the white ${ }^{+}\left(\mathrm{w}^{+}\right)$marker. Several independent transgenic lines were established with this construct. Since this transgene is expressed, in the absence of heat shock, in precisely the same cells as the constitutively active Sev ${ }^{S 11}$ kinase, it should rescue the suppression of $\mathrm{Su}\left(\mathrm{Sev}^{\mathrm{S11}}\right) R$ 1. Indeed, one copy of the $s E-h s p-d r k$ construct was sufficient to revert completely the suppression of $\mathrm{Sev}^{\mathrm{S11}}$ caused by the $\mathrm{Su}\left(\mathrm{Sev}^{S 11}\right) R 1$ or $E($ sev) $2 B$ allele (Figure $4 C$ ). These results indicate that the locus identified by the $S u\left(\operatorname{Sev}^{S 11}\right) R 1 / E(\mathrm{sev}) 2 B$ mutations encodes drk.

Transheterozygous combinations of $E(\operatorname{sev}) 2 B$ and $\mathrm{Su}\left(\mathrm{Sev}^{\mathrm{S11}}\right) R 1$ cause pupal lethality, suggesting that the
Figure 2. Comparison of the Distribution of sev and drk Transcripts in Eye imaginal Discs

(A) sev transcripts are only detected in a subpopulation of ornmatidiai precursor cells behind the morphogenetic furrow.

(B) High levels of drk transcripts are detected in all cells of the eye antennal disc. Scale bar, 40 $\mu \mathrm{m}$. drk gene plays an essential role in developmental processes other than R7 formation. To test whether the excessive lethality of $d r k$ mutations could be rescued by the ubiquitous expression of the $d r k$ cDNA, we crossed $E$ (sev)2B CyO females with $\mathrm{Su}\left(\mathrm{Sev}^{\mathrm{S} 11}\right) R 1$ /Sco males that contained the sE-hsp-drk construct. The progeny of these flies were subjected to repeated heat shock during development to induce general expression of the sE-hspdrk transgene. In the absence of heat shock, $E(\operatorname{sev}) 2 B$ / $\mathrm{Su}\left(\mathrm{Sev}^{\mathrm{S} 11}\right) R 1$ mutant animals containing the sE-hsp-drk transgene did not survive. However, if the cultures were heat shocked every $8 \mathrm{hr}$, the $E($ sev $) 2 B / S u\left(\operatorname{Sev}^{S 11}\right) R 1$ mutant animals survived to adults. These animals constituted $18 \%$ (150 of 821 ) of the total progeny class, in good agreement with the value of $12.5 \%$ that might be expected from this cross. Surviving flies were fully viable and fertile, demonstrating that ubiquitous expression of drk can rescue the recessive lethality of $E(\operatorname{sev}) 2 B$ / $\mathrm{Su}\left(\mathrm{Sev}^{\mathrm{S} 11}\right) R 1$ mutations

The Su(Sev $\left.{ }^{S 11}\right) R 1$ and E(sev)2B Mutations Affect Highly Conserved Drk SH2 Residues

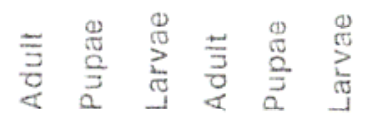



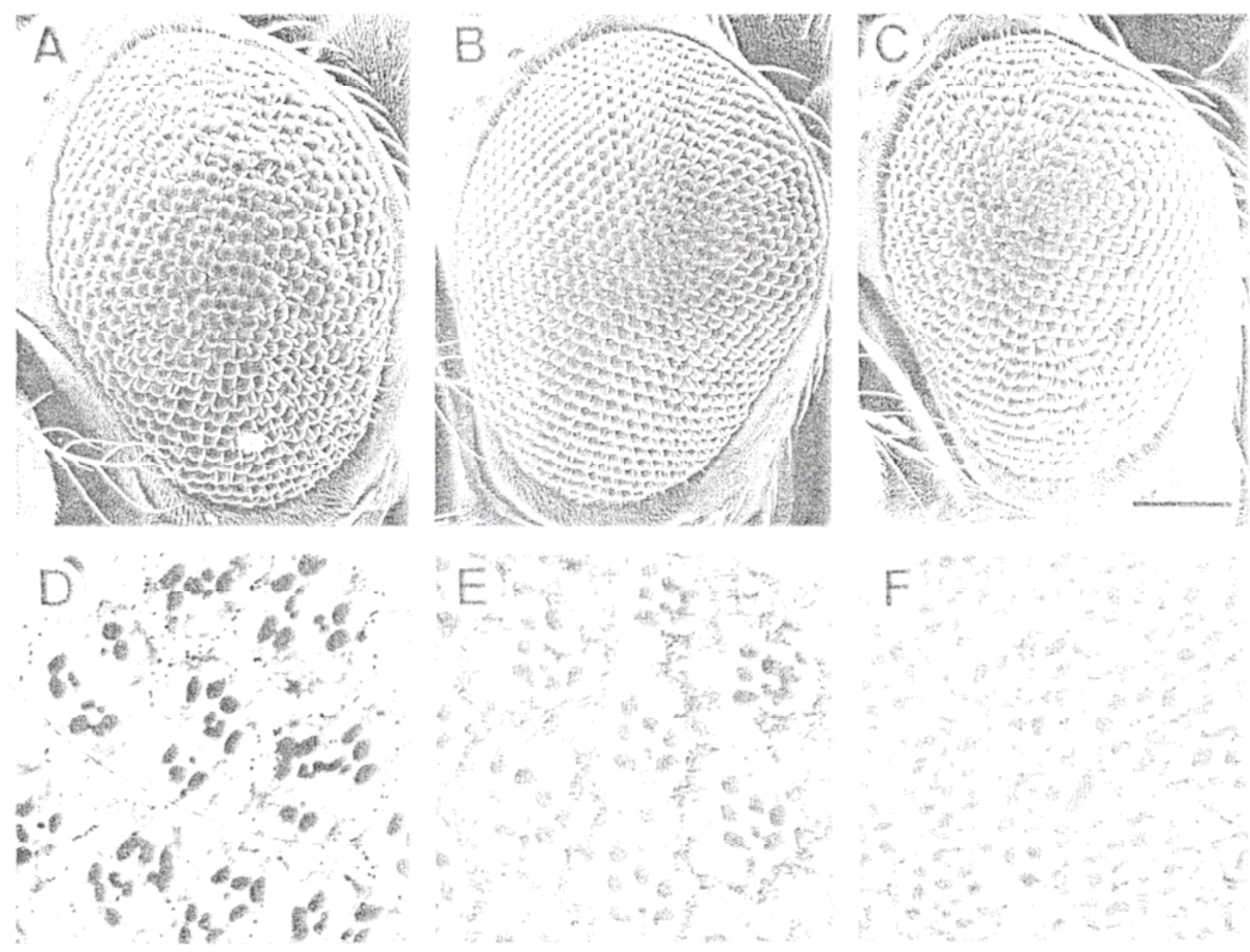

Figure 4. Expression of Drk under Control of the sev Enhancer Rescues the Dominant Suppression of the Sev ${ }^{\mathrm{s} 11}$ : Rough Eye Phenotyoe by Su(Sev $\left.{ }^{\mathrm{s11}}\right) R 1$

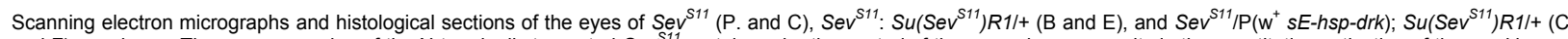
and F) are shown. The overexpression of the $\mathrm{N}$-terminally truncated $\mathrm{Sev}^{\mathrm{S11}}$ protein under the control of the sev enhancer results in the constitutive activation of the sev kinase. This causes the recruitment of multiple R7 cells per ommatidium and concomitant roughening of the eye surface (A and D). Reducing the number of functional gene copies of $\mathrm{Su}\left(\mathrm{Sev}^{S 11}\right) R$ 1 suppresses the formation of multiple R7 cells and the rough eye phenotype (B and $\mathrm{E}$ ) This suppression is rescued by expression of the drk cDNA under the control of the sev enhancer (C and F), indicating that the Su(Sev $\left.{ }^{S 11}\right) R 1$ locus encodes the drk protein. Scale bar, $100 \mu \mathrm{m}$ in $(\mathrm{C})$ and $10 \mu \mathrm{m}$ in $(\mathrm{F})$

The ability of the drk CCNA to suppress the phenotypic effects of the $S u\left(\mathrm{Sev}^{\mathrm{S} 11}\right) R 1$ and $E(\mathrm{sev}) 2 B$ mutations strongly suggested that these mutations might reside within the drk gene. We therefore analyzed the genomic sequence of drk from flies heterozygous for the Su $\left(\operatorname{Sev}^{S 11}\right) R 1$ or $E($ sev $) 2 B$ mutations (see Experimental Procedures). Figure $1 \mathrm{C}$ illustrates the genomic organization of $d r k$. Sequence analysis revealed a guanine to adenine change in $\mathrm{Su}\left(\mathrm{Sev}^{\mathrm{S11}}\right) \mathrm{R} 1$ (corresponding to nucleotide 500 in the cDNA sequence in Figure $1 \mathrm{~A}$ ), and acytosine to thymidine change in $E(\mathrm{sev}) 2 B$ (corresponding to nucleotide 616 in the cDNA sequence). Both these mutations are transitions, as expected from the mutagenic action of ethyl methanesullonate. In each case the mutation resides within the sequence coding for the $\mathrm{SH} 2$ domain. Specifically, in the product of the $S u\left(\mathrm{Sev}^{S 11}\right) R 1$ allele an arginine at position 67 is changed to a histidine, and in the $E$ (sev)2B product a histidine at position 106 is changed to a tyrosine. These two residues are highly conserved among $\mathrm{SH} 2$ domains, and from X-ray crystallographic analysis of the $\mathrm{Src} \mathrm{SH} 2$ domain seem to play a critical role in both phosphotyrosine binding arid also, in the case of the conserved histidine, in maintaining the overall structure of the SH2 domain (Waksman el al., 1992). These results confirm that the phenotypic effects caused by the $E($ sev $) 2 B$ and $S u\left(\operatorname{Sev}^{S 11}\right) R 1$ alleles are due to mutations in the $d r k$ gene.

The Drk Protein Rinds to Receptor Tyrosine Kinases

The initial drk cDNA was isolated by binding of its encoded Sti2 domain to the human EGF receptor. To confirm the ability of the drk protein to associate with activated receptor tyrosine kinases, drk was expressed in bacteria $2 \mathrm{~s}$ a glutathione S-transferase (GST) fusion protein and bound to glutathione-agarose beads. The immobilized GST-drk fusion protein was then incubated with lysates of rat-1 fibroblasts engineered lo overexpress the human EGF receptor. The GST-drk polypeptide formed a physical complex with the autophosphorylated EGF receptor form EGF-stimulated cells, but not from unstimulated cells (Figure 5A). 

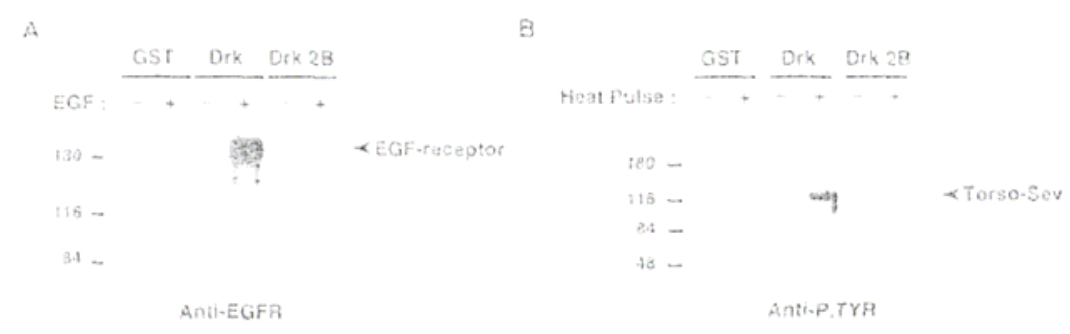

c

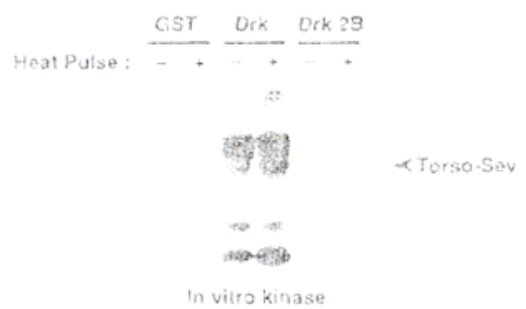

Figure 5. Binding of Wild-Type and Mutant Drk to Receptor Tyrosine Kinases

(A) Drk binding to human EGF receptor in vitro. R1hER cells were serum Starved: unstimulated cells (-) or cells stimulated with EGF (+) were lysed and incubated with GST, GST-drk (drk). or GST$\mathrm{drk}^{E(\mathrm{sev}) 2 B}$ (Drk 2B) fusion proteins immobilized on glutathione-agarose beads. EGF receptor association was detected by immunoblting with asti-GF ras anti-EGF receptor antibodies. The arou indicates the porition of tile EGF receptor.

(B and C) Drk binding to Drosophila torso-sev chimeric receptor in vltro. Transgenic flies expressing the torso-sev chimeric protein under control of the $h s p 70$ promoter were uninduced (-) or heat shocked $(+)$ and homogenized. Clarified lysates were incubated with immobilized GST, GST-drk (drk). or GST-drk ${ }^{E(s e v) 2 B}$ fusion proteins, and associated torso-sev was identified by immunoblotting with anti-phosphotyrosine imm antibodies (B) or by subjecting the complexes to in vitro kinase reactions $(C)$.

(D) Drk binding to torso-sev In vivo. Lysates of uninduced (-) or heat-shocked (T) flies were irnmunoprecipitated with anti-drk or anti-sev antibodies, and the immune complexes were subjected to in vitro kinase reactions. The mobility of torso-sev tyrosine kinase detected by autophosphorylation, is indictated.
To examine the ability of drk to bind activated sev tyrosine kinase, a chimeric torso-sev polypeptide was inducibly expressed in transgenic Drosophila sing the heat shock promoter. Torso-sev possesses a cytoplasmic sev tyrosine kinase domain, which is constitutively activated by its fusion to the extracellular domain of a gain-offunction mutant of the torso receptor tyrosine kinase (Sprenger and Nijsslein-Volhard, 1992; Dickson et al., 1992a). immobilized GST-drk fusion protein was incubated with uninduced or heat-shocked Drosophila lysates, and the resulting complexes were immunoblotted with anti-phosphotyrosine antibodies to identify autophosphorylated torso-sev. The GST-drk fusion protein specifically bound tyrosine-phosphoryiated torso-sev in lysates of heat-shocked flies (Figure 5B). Association of GST-drk with torso-sev from heat-shocked flies was also detected by incubating the complexes in kinase reactions to allow in vitro autophosphorylation of torso-sev (Figure $5 \mathrm{C})$.

The association of drk with torso-sev in vivo was investigated by immunoprecipitating lysates of uninduced or heat-shocked flies with anti-drk or anti-sev antibodies. Torso-sev was identified in these immunoprecipitates by its ability to autophosphorylate in vitro. The torso-sev tyrosine kinase was present in both anti-sev and anti-drk immunopecipitates from heat-shocked flies (Figure 5D). Similar results were obtained by immunobloting these immunoprecipitates with anti-phosphotyrosine or anti-sev antibodies (data not shown). These results indicate that wild-type drk associates with the activated torso-sev tyrosine kinase in flies.

The effect of the amino acid substitution (His-106 $\rightarrow$ Tyr) introduced into the drk $\mathrm{SH} 2$ domain by the $E(\mathrm{sev}) 2 B$ mutation was investigated by incorporating this change into the GST-drk fusion protein, and examining its effect on receptor binding. Unlike the wild-type drk polypeptide, the mutant protein failed to bind in vitro to either the autophosphorylated EGF receptor (Figure 5A) or the activated torso-sev chimeric receptor (Figures 5B and 5C). The ability of drk to bind autophosphorylated receptors is therefore compromised by the substitution in the $\mathrm{SH} 2$ domain induced by the $E($ sev $) 2 B$ mutation.

An Amino Acid Substitution in the SH2 Domain Alters the Subcellular Localization of the Drk Protein

The results presented above suggest that drk functions in the development of photoreceptors, and at other stages of Drosophila development, to couple receptor tyrosine kinases to one or more downstream signaling pathways. To investigate the expression of drk protein in ommatidial precursor cells, whose development is obstructed by the $\mathrm{Su}\left(\mathrm{Sev}^{\mathrm{S1}}\right) R 1$ and $E(\mathrm{sev}) 2 B$ mutations, wild-type Drosophila eye imaginal discs were immunostained with affinity purified anti-drk antibodies. As was expected from the in situ localization of RNA transcripts, the drk protein was expressed at high levels in all cells of the eye antennal disc. drk was localized at the plasma membrane in the apical portions of the epithelial imaginal disc cells. Figure $6 \mathrm{~A}$ shows a projection of a series of confocal sections through an eye imaginal disc, probed with antidrk antibodies. Immunofluorescent staining was primarily observed at the outer membrane of all cells in the imaginal disc. In the cells of the epithelium proper, the most intense staining was observed in the most apical $5 \mu \mathrm{m}$ of each cell. In the morphogenetic furrow (Figure 6A, black arrow) the diameters of the cells are reduced, owing to the apical constriction associated with the moving furrow. Behind the morphogenetic furrow, a consistently higher level of staining was observed in a subpopulation of developing 

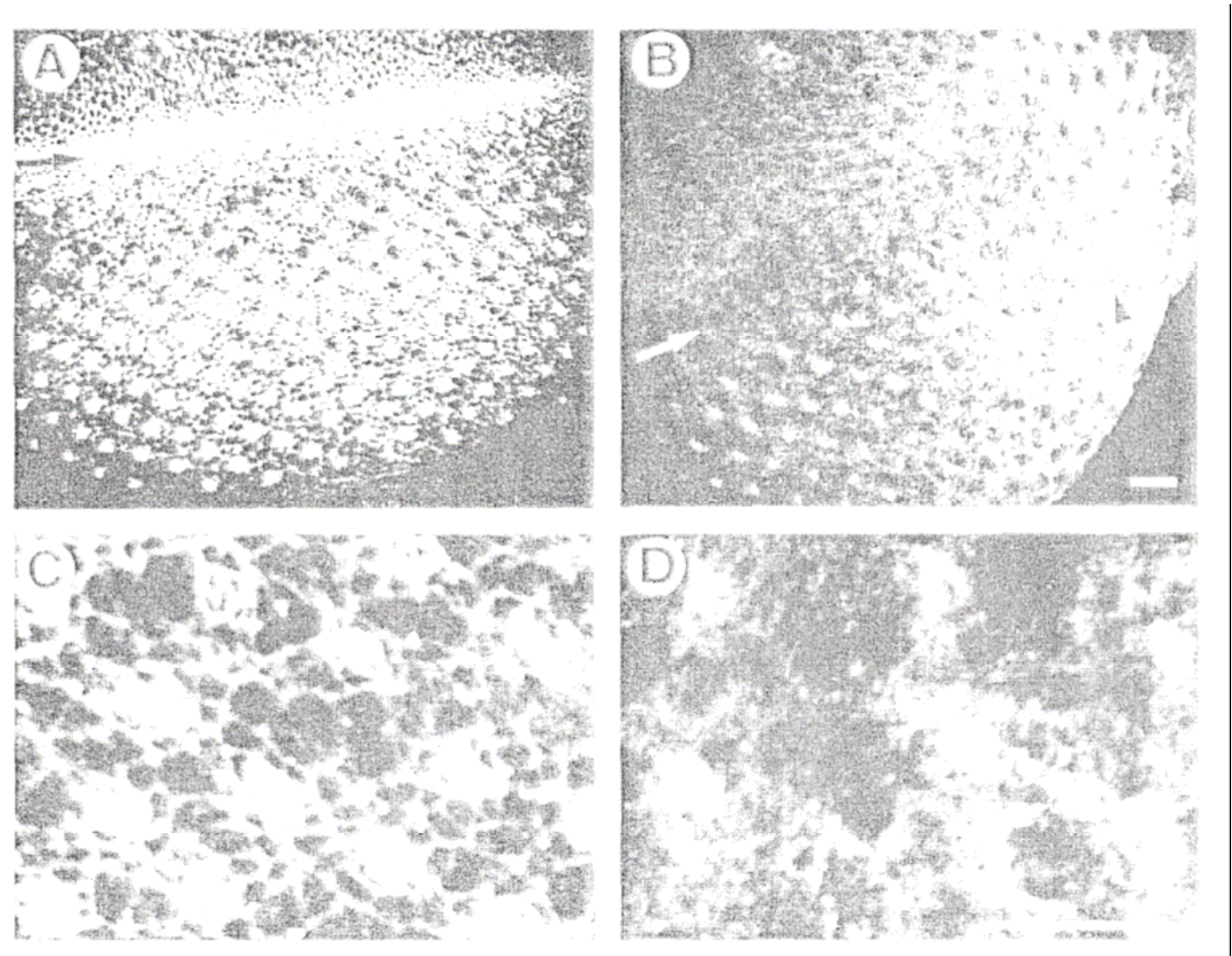

Figure 6. Localization of Wild-Type and Mutant Drk Protein in Eye Imaginal Discs

Projections of optical sections of eye imaginal discs of wiid-type (A and C) and $E(\operatorname{sev}) 2 B$ mutant larvae (5 and D) stained with affinity-purified anti-drk antibodies are shown Wild-type drk protein is highly concentrated at the apical membrane of all imaginal disc cells. In the morphogenetic furrow (black arrow in [A]) the density of ommatidial cells is higher, owing to their apical constriction in the furrow. Behind the morphogenetic furrow drk marks the assembly of the ommatidial clusters and is expressed at higher levels in a subpopulation of developing photoreceptor cells (C). The drk ${ }^{E(s e v) 2 B}$ protein, that carries a histidine to tyrosine amino acid substitution in the SH2 domain, is expressed at a subpopulation of developing photoreceptor cells (C). The drk protein, that carries a histidine to tyrosine amino acid substitution in the $\mathrm{SH} 2$ domain, is expressed at
similar levels as the wild-type protein but is not associated with the cell membrane. Rather, it is localized in the cytoplasm. The black arrow head in (6) indicates the cytoplasmic drk staining in the flat cells of the peripodial membrane. Since drk is required for imaginal disc development, ommatidial assembly in $E$ (sev) $2 B$ discs is abnormal. However, higher levels of mutant protein are still observed in cell clusters behind the morphogenetic furrow (white arrow in [B]). Scale bar, $10 \mu \mathrm{m}$.

photoreceptor cells. A higher magnification of anti-drk labeling is shown in Figure 6C.

Since the sev receptor tyrosine kinase is also restricted to the cell membrane in the apical region of a subpopulation of developing ommatidial cells, the physical association of drk and sev, demonstrated above, might contribute to drk localization in these cells. Clearly, however, the membrane localization of drk is not exclusively due to sev binding since sev is only expressed transiently in a small subpopulation of imaginal disc cells and is only activated in a single cell, the R7 precursor. Furthermore, no alteration in the membrane localization of the drk protein was observed in eye discs derived from sev mutant larvae (data not shown).

The involvement of the drk Ski2 domain in localization to the membrane could be directly tested, since drk encoded by the mutant $E(\mathrm{sev}) 2 B$ allele contains an amino acid substitution of a highly conserved residue required for phosphotyrosine binding. Animals homozygous for $\mathrm{drk}^{E(\mathrm{sev}) 2 B}$ die at the pupal stage: imaginal discs of homozygous $\mathrm{drk}^{E(\operatorname{sev}) 2 B}$ larvae reduced in size, and the assembly of the ommatidial clusters is abnormal. Compared with anti-drk staining of the wild-type disc, no appreciable loss in the overall intensity of immunofluorescence was observed in the $\mathrm{drk}^{E(\mathrm{sev}) 2 B}$ homozygous mutant discs. however, the pronounced straining of the apical membrane portions of each cell, observed in wild-type eye discs, was not detected in mutant discs. In contrast, the immunofluorescence was more cytoplasmic (Figure 6B), as evident in the flat cells of the peripodial membrane (black arrowhead in Figure 6B). Although ommatidial assembly in $E($ sev $) 2 B$ flies is abnormal, higher levels of mutant drk protein are still observed behind the morphogenetic furrow (Figure 6D). These results suggest that localization of the drk protein to the apical portion of the cell membrane requires a functional $\mathrm{SH} 2$ domain. These observations are consistent with the view that drk is recruited to the plasma membrane by binding of its $\mathrm{SH} 2$ domain to membrane associated phosphotyrosine-containing proteins, such as activated receptor tyrosine kinases. 


\section{Drk Binds to the C-Terminal Tail of Sos}

The identification of drk as a gene required for sev signaling, and the ability of the drk $\mathrm{SH} 2$ domain to bind activated receptor tyrosine kinases, suggests that the drk protein is a target of sev. Other loci, including Sos and Ras1, have been identified in genetic screens as being required for signaling downstream of sev (Simon et al., 1991; Rogge et al., 1991). Sos encodes a polypeptide with a centrally located domain related in sequence to the CDC25 gene product of Saccharomyces. cerevisiae, which catalyzes the exchange of GDP for GTP on Ras, thereby leading to Ras activation. Genetic analysis suggests that the Sos protein may act downstream of sev as a GNRP for Ras1 during Drosophila development. Given that drk also lies in this pathway and can bind directly to activated receptors, it is possible that drk links receptor tyrosine kinases to Sos, which in turn controls the activation of Ras 1 . If the drk $\mathrm{SH} 2$ domain mediates its interactions with activated receptors, then the $\mathrm{SH} 3$ domains, which make up the remainder of the protein, are likely to provide binding sites for targets immediately downstream of drk. Recent evidence has suggested that the $\mathrm{SH} 3$ domains of $\mathrm{Abl}$ and $\mathrm{Src}$ can bind to a proline-rich motif in the protein 3BP-1 (APTMPPPLPP), containing the sequence PPPLPP (Cicchetti et al., 1992; Ren et al., 1993). nuclear magnetic resonance analysis of the Src $\mathrm{SH} 3$ domain complexed with a peptide corresponding to the 3BP-1 SH3-binding site suggests that these prolines may directly contact the SH3 domain (Yu et al., 1992). In Sos, the 505 amino acid sequence C-terminal to the CDC25-like domain is relatively rich in proline residues (15\%) (Simon et al., 1991), and contains several sequences related to the $3 \mathrm{BP}-1 \mathrm{SH} 3-$ binding site (Figure 7A).

We therefore tested the ability of drk to associate physically with Sos. Bacterial GST-Sos fusion proteins were expressed that contained either residues 1225-1405 within the C-terminal tail of Sos (Sos tail), including three of the proline-rich sequences noted in Figure $7 \mathrm{~A}$, or residues 505-692 from the amino-terminal region (Sos $\mathrm{N}$ ). Lysates of bacteria expressing the parental GST protein, or the GST-Sos fusion proteins, were separated by SDSpolyacrylamide gel electrophoresis (SDS-PAGE) and transferred to a nitrocellulose filter. The filter was then incubated with drk protein purified from bacteria. Drk bound specifically to the immobilized GST-Sos tail protein, but did not recognize GST or the GST-Sos $N$ polypeptides, nor any other bacterial proteins (Figure 78). In a complementary experiment, the GST-Sos tail protein, immobilized on beads, bound specifically to drk in Drosophila lysates (Figure 7C). These results demonstrate that drk has an intrinsic affinity for the C-terminal tail of Sos.

\section{Discussion}

A Protein with St12 and SH3 Domains Functions in Signal Transduction during Drosophila Development We have isolated a Drosophila cDNA encoding a protein with the structure $\mathrm{SH} 3-\mathrm{SH} 2-\mathrm{SH} 3$, and have identified this gene product as the Drosophila homolog of Sem-5 and GRB2. We have used both genetic and biochemical techniques to investigate the role of drk in the sev receptor tyrosine kinase signal transduction pathway, which controls the specification of R7 photoreceptor cell fate.
A

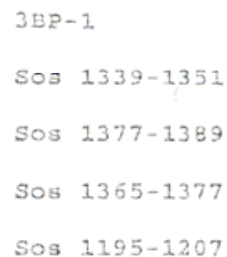

Sos 1195-1207

B

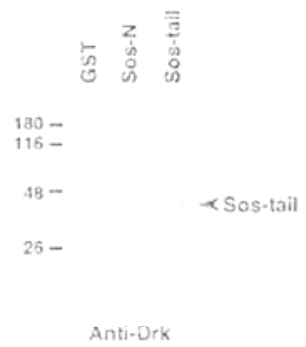

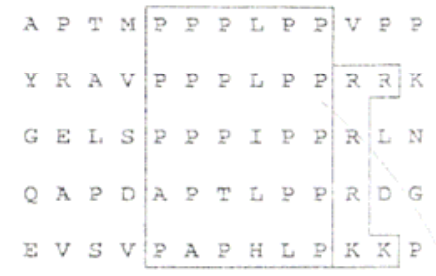

$\mathrm{C}$
Figure 7. Drk Binds to the Tail of Sos

(A) The C-terminal tail of Sos contains potential SH3-binding sites. A sequence encompassing the Abl SH3-binding site in the protein 3BP-1 is compared with motifs in the C-terminal region of Sos. A proline-rich element, postulated to occupy the SH3 ligand-binding site. 1s boxed. Basic residues following the proline-rich elements of Sos are also outlined.

(B) Bacterial lysates expressing GST, GST-Sos N, and GST-Sos tail were fractionated by SDS-PAGE and transferred to nitrocellulose. This filter was then incubated with purifed bacterial drk protein. Binding of drk was detected by immunoblotting with anti-drk antibodies. An arrow indicates the mobility of the GST-Sos tail.

(C) Protein lysates of torso-sev transgenic Drosophila, either uninduced (-) or heat shocked $(+)$, were incubated with immobilized GST-Sos tail, and complexes were analyzed by immunoblotting with anti-drk antibodies. The position of drk is indicated.

Simon et al. (1993 [this issue of Cell]) have also identified the drk gene and have demonstrated its involvement in signaling between sev and Ras1.

The cytological map position of the gene encoding the drk protein suggested that it might correspond to the $E\left(\right.$ sev)2B/Su(Sev $\left.{ }^{S 11}\right) R 1$ locus, in which loss-of-function mutations have been identified either as dominant enhancers of a weak sev mutation or as suppressors of the gain-of-function mutation Sev ${ }^{S 11}$. Indeed, expression of the drk cDNA under the control of the sev enhancer and heat shock promoter rescued the dominant suppression of the Sev ${ }^{S 11}$ phenotype by the $S u\left(\operatorname{Sev}^{S 11}\right) R 1$ mutation. Repeated heat shock induction of drk rescued the lethality of combined $E(\mathrm{sev}) 2 \mathrm{~B} / \mathrm{Su}\left(\mathrm{Sev}^{\mathrm{S11}}\right) \mathrm{R} 1$ mutations. Previous genetic analysis has indicated that the product of this gene is required for signaling by both the sev and DER receptor tyrosine kinases (Simon et al., 1991). Although embryos lacking DER function do not develop to the larval stage (Schejter and Shilo, 1989; Price et al., 1989), loss of drk function results in pupal lethality. It is possible that drk mutant larvae can survive to the pupal stage in the absence of zygotically produced protein owing to maternal product that is deposited in the egg. Consistent with this hypothesis, a relatively high level of drk RNA can be detected by in situ hybridization in unfertilized eggs (data not shown). Furthermore, it has been shown that drk function is required maternally for signaling from the torso 
receptor tyrosine kinase during early embryonic development (Doyle and Bishop, 1993). Therefore the drk protein appears to serve an essential function in the signal transduction patbways activated by different receptor tyrosine kinases.

\section{The SH2 Domain Links Drk to Activated Receptor} Tyrosine Kinases

Sequencing of the drk gene from Drosophila carrying the $E($ sev $) 2 B$ or $S u\left(\mathrm{Sev}^{S 11}\right) R 1$ alleles identified mutations in each allele, both of which introduce amino acid substitutions into the drk $\mathrm{SH} 2$ domain. On purely theoretical grounds, both of these substitutions would be expected to impair the ability of the drk $\mathrm{SH} 2$ domain to bind to phosphotyrosine-containing polypeptides. In the $E$ (sev) $2 B$ product His-106 is changed to tyrosine. This histidine (His $\beta D 4$ by the nomenclature of Eck et al. [1993]), is conserved in all but one of the known $\mathrm{SH} 2$ domains (Koch et al., 1991), and the homologous residue in the $\mathrm{Src} \mathrm{SH} 2$ domain (His-201 of the Src protein) plays a crucial role in forming the phosphotyrosine-binding site. The X-ray crvstallographic structure of the $\mathrm{Src} \mathrm{SH} 2$ domain bound to phosphotyrosine-containing peptides reveals that the His-201 side chain interacts with phosphotyrosine (J. Kuriyan, personal communication). His-201 serves as a platform to position Arg-155 (Arg $\alpha \mathrm{A} 2$ ), which also makes direct contact with the phosphotyrosine (Waksman et al., 1992). In addition, His201 forms hydrogen bonds with Glu-159 (Glu aA6), in the first a helix, and with Ser-187 (Ser pC5) in the third $\beta$ strand. Hence, His-201 appears to be important in dictating the overall structure of the $\mathrm{Src} \mathrm{SH} 2$ domain, as well as in forming the phosphotyrosine-binding site. Consistent with this view, incorporation of the $E(\operatorname{sev}) 2 B$ mutation into the GST-drk fusion protein abrogated its ability to bind the activated torso-sev tyrosine kinase and autophosphorylated EGF receptor in vitro. We have previously noted that substitution of the homologous histidine in the N-terminal GAP SH2 domain compromises its binding to growth factor receptors in vitro (Marengere and Pawson, 1992).

The Su(Sev $\left.{ }^{S 11}\right) R 1$ mutation also affects a highly conserved residue in the drk $\mathrm{SH} 2$ domain (Arg-67), which corresponds to Arg-155 of Src (Arg aA2). In the Src SH2 domain, this residue forms an important element of the phosphotyrosine-binding site. A nitrogen of the terminal guanidinium group interacts with the electron density of the tyrosine ring, while the intrachain (c) nitrogen makes a hydrogen bond with a phosphate oxygen (Waksman et al., 1992).

These results indicate that the ability of the drk $\mathrm{SH} 2$ domain to recognize phosphotyrosine is essential for drk biological activity. It is of interest to note that the mammalian hornolog of drk, GRB2, is not normally a substrate for tyrosine phosphorylation, even in cells stimulated with growth factors or transformed with oncogenic tyrosine kinases (Lowenstein et al., 1992: Rozakis-Adcock et al., 1992). Similarly, drk immunoprecipitated from lysates of Drosophila expressing the torso-sev tyrosine kinase did not contain detectable phosphotyrosine (data not shown). It is therefore likely that the function of GRB2 and drk is regulated not by phosphorylation, but by direct binding of their $\mathrm{SH} 2$ domain to autophosphorylated receptors or other phosphotyrosine-containing proteins, such as the SHC gene products (Rozakis-Adcock et al., 1992).
Irnmunostaining of imaginal discs from wild-type and $E$ (sev)2B mutant larvae shows that the wild-type drk protein is predominantly associated with the apical membrane of irnaginal disc cells, whereas the mutant drk protein, lacking a functional SH2 domain, is localized in the cytoplasm. Hence, receptor autophosphorylation may serve as a means to recruit drk, arid any drk-associated proteins, to their presumed site of action at the membrane.

\section{Drk Is Implicated in Coupling Receptor Tyrosine} Kinases to Sos

The identification of Sos and Ras1 as genes required for sev signaling suggested the possibility that drk might couple receptor tyrosine kinases to Sos, which has a central domain related to CDC25, and is therefore likely to act as a Ras GNRP. The tail of Sos, C-terminal to the CDC25 domain, has several proline-rich sequences related to the SH3-binding site identified in 3BP-1, which might serve as contact sites for the $\mathrm{SH} 3$ domains of drk. Indeed, we found that purified drk bound specifically to the C-terminal tail of Sos in vitro.

These results suggest that one function of drk is to couple activated receptor tyrosine kinases, which it binds through its $\mathrm{SH} 2$ domain, to Sos, which it complexes with its SH3 domains. Indeed, substitution of a conserved proline in the C-terminal drk $\mathrm{SH} 3$ domain reduced its ability to bind the Sos tail (J. P. O., unpublished data). The provision of drk with two $\mathrm{SH} 3$ domains may increase its affinity for Sos, if these domains bind cooperatively to sites within the Sos tail. The Sos GNRP, in turn, can potentially activate Ras 1 by catalyzing the exchange of GDP for GTP (Figure 8). This scheme proposes that the binding of the drk $\mathrm{SH} 2$ domain to autophosphorylated receptors serves to activate Sos guanine nucleotide exchange activity in vivo. This might be achieved simply by relocalizing drk associated Sos to the membrane, where Ras proteins are located. It is also possible that Sos activity is stimulated following binding of drk to a receptor, either by a conformational change transmitted through the $\mathrm{SH} 3$ domains or by tyrosine phosphorylation of Sos.

Recently, two mouse cDNAs encoding proteins very closely related to Drosophila Sos have been isolated (Bowtell et al., 1992). The mouse Sos 1 and Sos 2 proteins both have proline-rich tails with multiple potential SH3binding sites. It is of interest that in the Sos proteins from both Drosophila and mouse, the C-terminal proline-rich sequences are invariably followed by one or more basic residues (usually an arginine; see Figure $7 \mathrm{~A}$ ), which might provide an element of specificity for the GRB2/drk SH3 domains. Given the evolutionary conservation of tyrosine kinases, the drk/Sem-5/GRB2 family, Sos, and Ras, it seems probable that the model outlined in Figure 8 will prove to be a general mechanism by which receptor tyrcsine kinases communicate with Ras proteins.

\section{Experimental Procedures}

Isolation and Analysis of cDNA Clones

The intracellular domain of the human EGF receptor produced in a recombinant baculovirus expression system was autophosphorylated using $\left[\gamma^{-32} \mathrm{P}\right] \mathrm{ATP}$, followed by cleavage with cyanogen bromide as previously described (Skolnik er al., 1991; Margolis et al., 1992). The ${ }^{32} \mathrm{P}$-radiolabeled carboxy-terminal EGF receptor tail was then used to probe a Drosophila 10-12 hr embryonic cDNA expression library (Novagen), constructed in the Ex-Lox bacteriophage vector as previously described (Margolis et al., 1992). Out of approximately $1.4 \mathrm{x}$ $10^{6}$ phage screened, one clone (dAA) was isolated through the ability 


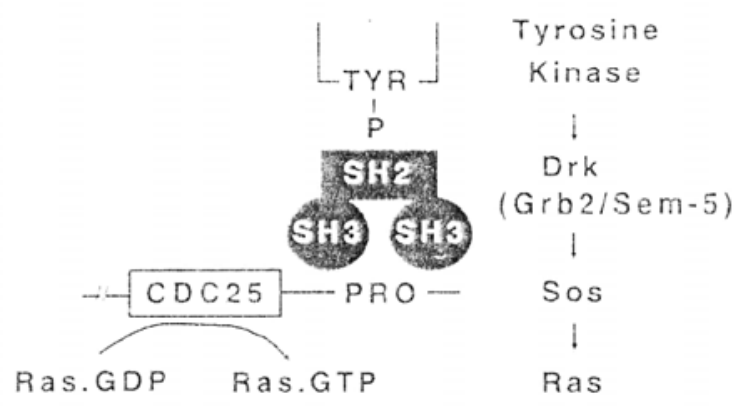

Figure 8. A Model for the Role of Drk in Coupling-Activated Receptor Tyrosine Kinases to Sos

Drk is illustrated as binding to a phosphotyrosine-containing site on an activated receptor through its SH2domain and to proline-rich motifs (PRO) in the tail of Sos through its SH3 domains. This interaction may serve to localize Sos to the membrane, where it can gain access to GDP-bound Ras, and might also stimulate Sos activity in vivo.

of its product to bind to the EGF receptor tail. Additional overlapping drk cDNA clones were obtained by screening the same library with clone dAA as a probe using standard DNA hybridization protocols. DNA sequence analysis was performed on plasmid subclones using the Sequenase system (United States Biochemical Corporation).

Polymerase Chain Reaction Amplification and Sequence Analysis of drk Genomic DNA

Polymerase chain reaction (PCR) amplification was performed on genomic DNA extracted from Drosophila heterozygous for either the $\mathrm{Su}\left(\mathrm{Sev}^{\mathrm{S11}}\right) R 1$ or the $E(\mathrm{sev}) 2 B$ mutations, as well as from the parental strain w1118, CyO/Sco. 'The drk genomic locus was too large to amplify in a single PCR. Oligonucleotide primers derived from the drk CDNA sequence and based on the genomic organization of sem-5 (Clark et al., 1992) were therefore synthesized. Three sets of primers, D1 (GCATCAAGGCTGATAG) and D2 (TTGCAGTGCCCCCTTCAGTGTG

D3 (GCAGGGGTAGAAGATTTAG) and D4 (AATTACTAGGTATGAG), and D5 (TCAAATTGGTATCGCGCGGAG) and D6 TTATGAATGATATGG), were used to amplify the drk locus (Figure $1 \mathrm{C})$. Each reaction was done in duplicate to minimize PCR artifacts. All PCRs werecarried out under the following conditions: $100 \mathrm{ng}$ of genomic DNA and $500 \mathrm{ng}$ of each primer were denatured at $94^{\circ} \mathrm{C}$ annealed at $55^{\circ} \mathrm{C}$, and polymerized with pfu (Stratagene) at $72^{\circ} \mathrm{C}$ for 30 cycles on a Perkin Elmer thermal cycler. The resulting PCR products were subcloned into the pCRII vector (Invitrogen), and multiple clones were sequenced.

5 ' sequences of wild-type genomic drk were obtained from cloned DNA, isolated by screening a Drosophila genomic library constructed in $\lambda$ DASHII (Stratagene) (kindly provided by M. Noll) with a full-length drk cDNA. Plaque hybridization and analysis of the positive phage clones were done according to standard protocols.

\section{In Situ Hybridization}

Digoxigenin-labeled DNA probes were prepared by random priming according to the Boehringer Mannheim Application Manual, with the exception that a 20 -fold higher hexanucleotide concentration was used. Eye imaginal discs were dissected in Ringer's and fixed for 15 $\min$ in $4 \%$ paraformaldehyde. $0.2 \%$ Tween- $20,0.2 \%$ sodium deoxycholate. Hybridization and detection were carried out as described (Tautz and Pfeifle, 1989). The discs were mounted in Moviol-2.5\% DAPCO.

A similar probe was used for in situ hybridization to polytene chromosomes (Ashburner, 1989).

\section{Generation of Antibodies}

Full length drk cDNA was cloned into the pET11d expression vector (Novagen) and into the pGEX2T vector (Pharmacia) to make nonfusion and GST fusion proteins, respectively. PCR was used to create restriction endonuclease sites to facilitate cloning of drk coding regions into the expression vectors. Specifically, $\mathrm{Ncol}\left(5^{\prime}\right)$ and BamHI (3') sites were employed to clone drk into pET11d, whereas BamHI $\left(5^{\prime}\right)$ and EcoRI (3') sites were added to clone drk into pGEX2T. The resulting PET-drk clone was transformed into BL21 DE3 Escherichia coli and pGEX-drk was transformed into $\mathrm{DH} 5 \alpha \mathrm{E}$. coli. Recombinant protein was induced for $4 \mathrm{hr}$ with $1 \mathrm{mM}$ isopropyl- $\beta$-D-thiogalactopyranoside, starting when the bacterial culture reached an $\mathrm{OD}_{600}$ of $0.5-0.8$. Bacterial pellets were sonicated three times for $20 \mathrm{~s}$ each in phospholipase C lysis buffer (50 mM HEPES [pH 7.51, $150 \mathrm{mM}$ sodium chloride, 10Vo glycerol, $1 \%$ Triton X-100, $1 \mathrm{mM}$ EGTA, $1.5 \mathrm{mM}$ magnesium chloride, $100 \mathrm{mM}$ sodium fluoride, $10 \mathrm{mM}$ sodium pyrophosphate, and $10 \mathrm{pgl} \mathrm{ml}$ aprotinin and leupeptin) and clarified by centrifugation. The clarified lysate of bacteria induced to express the PET-drk clone was boiled in SDS sample buffer $(50 \mathrm{mM}$ Tris- $\mathrm{HCl}[\mathrm{pH}$ $6.81,2 \%$ SDS [w/v], $10 \%$ glycerol, and 5\% $\beta$-mercaptoethanol) and separated by electrophoresis on a preparative SDS-polyacrylamide $(15 \%)$ gel. The resulting nonfusion drk protein was excised, electroeluted, and used togenerate rabbit polyclonal antibodies (antidrk). GST-drk fusion protein was purified using glutathione-agarose and eluted with $10 \mathrm{mM}$ glutathione as described previously (Pelicci et al., 1992). The rabbit polyclonal antibody was affinity purified from crude sera using purified GST-drk protein. Anti-sev antiserum (G39-20) was directed against the C-terminal portion of sev. Polyclonal rabbit anti-EGF receptor antibody has beer] described (Honegger et al., 1989).

\section{Western Blotting and Immunoprecipitation}

For immunoblotting of total Drosophila protein lysates. adult flies. Pupae or larvae were homogenized in SDS sample buffer. Rat fibroblasts overexpressing human EGF receptor (R1hER) were maintained in Dulbecco's modified Eagle's medium containing $10 \%$ fetal calf serum. For growth factor stimulation, cells were serum starved for $24 \mathrm{hr}$ In DMEM $+0.5 \%$ fetal calf serum and then stimulated with $80 \mathrm{nM}$ EGF for $5 \mathrm{~min}$ and harvested. For immunoprecipitations, adult flies were homogenized, or R1hER cells were lysed in phospholipase C-.LB containing $1 \mathrm{mM}$ sodium orthovanadate and 1 $\mathrm{mM}$ phenylmethylsulfonyl fluoride. Lysates were clarified by centrifugation and incubated with $2 \mu \mathrm{g} / \mathrm{ml}$ affinity-purified anti-drk, or a 1:200 dilution of anti-sev, and protein A-Sepharose, for $90 \mathrm{~min}$ at doc, Immunoprecipitates were washed three times in $1 \mathrm{ml}$ of HNTG $(20 \mathrm{mM}$ HEPES [pH 7.5], $150 \mathrm{mM}$ sodium chloride, $10 \%$ glycerol, $0.1 \%$ Triton $\mathrm{X}-100$, and $1 \mathrm{mM}$ sodium orthovanadate), and then boiled for $5 \mathrm{~min}$ in SDS sample buffer. All samples were fractionated by electrophoresis on $7.5 \%, 10 \%$, or $15 \%$ SDS-polyacrylamide gels and transferred to nitrocellulose in a semidry blotting appara!us at $0.8 \mathrm{~mA} / \mathrm{cm}^{2}$ for $1 \mathrm{hr}$ Filters were blocked for $1 \mathrm{hr}$ at room temperature in $5 \%$ nonfat dry milk in TBS-T (20 mM Tris [pH 7.5], $150 \mathrm{mM}$ sodium chloride, and $0.05 \%$ Triton X-100) and probed with 2 pglml affinity-purified anti-drk or a 1:1000 dilution of anti-sev. For anti-phosphotyrosine immunoblots, filters were blocked in $5 \%$ bovine serum albumin, $1 \%$ ovalbumin in TBS-T, and probed with $1 \mu \mathrm{g} / \mathrm{ml}$ affinity-purified anti-phosphotyrosine antibodies. Anti-drk and anti-sev immunoblots were developed using either the epichemiluminescence kit (Amersham), alkaline phosphatase (Bio-Rad), or ${ }^{125}$ I-labeled protein A (Amersham). The antiphosphotyrosine immunoblots were processed using ${ }^{125}$ I-labeled protein A.

\section{In Vitro Binding Studies}

The $E$ (sev) $2 B$ mutation was introduced into the drk cDNA by PCR mutagenesis as described (Marengere and Pawson, 1992) and subcloned into the pGEX2T vector as above. The GST, GST-drk, or GST-drk ${ }^{E(s e v) 2 B}$ fusion proteins were induced and purified by binding to glutathione-agarose beads. R1hER cells or adult flies were lysed in phospholipase C-LB, clarified and incubated with immobilized GST or GST fusion proteins for $90 \mathrm{~min}$ at $4^{\circ} \mathrm{C}$. The protein complexes were washed three times with HNTG and boiled for 5 min in SDS sample buffer. Complexes were then resolved by SDS-PAGE and transferred to nitrocellulose. Filters were blocked and probed with antibodies as described above.

Protein complexes were also subjected to in vitro kinase assays, Both immune complexes and GST fusion protein complexes were incubated with $0.5 \mu \mathrm{Ci}$ of [ $\left.\mathrm{\gamma}^{-}{ }^{32} \mathrm{P}\right] \mathrm{ATP}$ in KRB (20 mM-HEPES [pH 7.4], $25 \mathrm{mM}$ magnesium chloride, . $4 \mathrm{mM}$ manganous chloride, and $0.1 \mathrm{mM}$ sodium orthovanadate) at room temperature for $15 \mathrm{~min}$. Reactions were stopped by adding an equal volume of 2 x SDS sample buffer A fraction of the kinase reaction was separated by SDS-PAGE, and the gel was fixed, dried, and exposed to film.

Two regions of Sos were subcloned by PCR into the pGEX2T vector: pGEX Sos N encodes arnino acids 505-692 and pGEX Sos tail encodes amino acids 1225-1405 of Sos. Crude bacterial extracts expressing GST, GST-Sos N, and GST-Sos tail bacterial fusion proteins were resolved by $10 \%$ SDS-PAGE and were transferred to nitrocellulose. Filters were blocked in TBS containing 5\% bovine serum albumin, $10 / 0$ ovalbumin, and $0.1 \%$ SDS for $1 \mathrm{hr}$. These filters were probed using purified drk protein from bacteria expressing drk for $3 \mathrm{hr}$ at room temperature and washed three times with TBS plus $0.1 \%$ 
SDS. Complexes were detected by immunoblotting using affinitypurified anti-drk antibodies.

\section{Imrnunohistochernistry and Confocal Microscopy}

Eye imaginal discs from late third instar larvae were dissected in Ringer's and fixed in $4 \%$ paraformaldehyde in $0.1 \mathrm{M}$ phosphate buffer $(\mathrm{pH} 7.0), 0.07 \mathrm{M}$ glucose, $0.07 \mathrm{M} \mathrm{CaCl}$, for $30 \mathrm{~min}$. The discs were washed in phosphate-buffered saline- $0.2 \%$ saponin, blocked for $30 \mathrm{~min}$ in phosphate-buffered saline- $0.2 \%$ saponin containing $3 \%$ fetal bovine serum, and incubated overnight with affinity-purifled anti-drk antibodies at $4^{\circ} \mathrm{C}$. The discs were then washed three times with phosphatebuffered saline- $0.2 \%$ saponin and then incubated with a fluorescein isothiocyanate-coniugated anti-rabbit antibody (1:80: Southern Biotech Inc.). After washing in phosphate-buffered saline- $0.2 \%$ saponin, the discs were mounted in $70 \%$ glycerol containing $2.5 \%$ DAPCO.

Optical sections of immunofluorescence were obtained using a confocal laser scanning microscope (Multiprobe 2001, Molecular Dynamics). Pictures were prepared by using the maximal intensity projection option (Imagespace software, Molecular Dynamics); photographs were taken off the screen.

\section{Drosophila Strains}

The genetic screen to identify suppressors of the Sev ${ }^{S 11}$ phenotype will be described in detail elsewhere (T. R, et al., unpublished data). In brief, males were mutagenized with ethyl methanesulfonate or by the mobilization of $P$ elements and crossed with females that were homozygous for a Sev ${ }^{\text {S11 }}$ construct on the third chromosome (Basler et al., 1991). The progeny were scored for individuals that exhibit suppression of the rough eye phenotype. $S u\left(\mathrm{Sev}^{\mathrm{S} 11}\right) R 1$ was mapped meiotically using the multiply marked chromosome $b \mathrm{pr} c n$ bw. $\mathrm{Su}\left(\mathrm{Sev}^{{ }^{11}}\right) R 1$ was shown to be allelic to $E(\mathrm{sev}) 2 B$ by complementation analysis. The chromosomal sites of integration of the $P$ elements were determined by in situ hybridization with a biotin-labeled $P$ elementspecific probe as described by Easier and Hafen (1988).

Flies carrylng a transgene encoding an activated torso-sev fusion protein (a fusion of the extracellular domain of torso ${ }^{4021}$ and the intracellular kinase domain of sev) under the control of the $h s p 70$ promoter in the pW8 transformation vector (Dickson et al., 1992a) were stimulated at $37 \%$ for $30 \mathrm{~min}$ and then allowed to recover at room temperature for $4 \mathrm{hr}$.

\section{Rescue Construct and Germline Transformation}

The $s E-h s p-d r k$ construct was made by inserting the full-length $d r k$ cDNA into a modified pW8 transformation vector (Klemenz et al., 1987 ), containing the $h s p 70$ promoter and a single copy of the $1.2 \mathrm{~kb}$ $s E$ fragment (Basler et al., 1991). Plasmid DNA was prepared for injection as described previously (Basler et al., 1991) The sE-hsp-drk construct was injected into W1118 host embryos. Nine independent transformed lines were established. To test whether ubiquitous expression of the drk cDNA could rescue the lethality of drk mutations, Su $\left(\mathrm{Sev}^{S 11}\right) R 1 / E(\mathrm{sev}) 2 B$; sE-hsp-drk transformant flies were shifted to $37^{\circ} \mathrm{C}$ for $40 \mathrm{~min}$ every $8 \mathrm{hr}$ during development.

\section{Scanning Electron Microscopy and Histology}

Adult flies for scanning electron microscopy were stored in $70 \%$ acetone before they were critical-point dried and coated for examination with a Hitachi s-4000 scanning electron microscope. Fixation and preparation of histological sections for light microscopy were performed as described previously (Basler and Hafen, 1988).

\section{Acknowledgments}

The first two authors contributed equally to this work. We thank Xiangdong Liu for the initial characterization of the $\mathrm{Su}\left(\mathrm{Sev}^{\mathrm{S}{ }^{11}}\right) R 1$ mutation, Michael Hoffmann for polytene chromosome spreads, Utpal Baneriee for the gift of Sos cDNA, Alex Singer for help in construction of the pET-drk expression vector, and Gerald Gish for purification of the pET-drk protein. We are grateful to Michael Simon and Gerald Rubin for providing the $E(\mathrm{sev}) 2 B$ allele and sequence information and for helpful discussions. This work was supported by grants from Bristol-Myers-Squibb, the National Cancer Institute of Canada (NCIC), and the Medical Research Council of Canada (MRC): by an International Scholar Award from the Howard Hughes Medical Institute to T. P.; by grants from the Human Frontier Science Program and Sugen Inc. (J. S.); by a grant from the Lucille P. Markey Charitable Trust (B. M.); and by a grant from the Swiss National Science Foundation to $E$. H.; T. R, is supported by an EMBO long-term fellowship. M. H. is supported by a postdoctoral fellowship from the MRC. T. P, is a Terry Fox Cancer Research Scientist of the NCIC.

Received February 4, 1993; revised March 4, 1993

\section{References}

Abraham, N., Miceli. M. C., Parnes, J. R., and Veillette. A. (1992). Enhancement of T-cell responsiveness by the lymphocyfe-specific tyrosine protein kinase p56lck. Nature 350. 62-66.

Appleby, M. W., Gross. J. A., Cooke, M. P., Levin, S. D., Qian, X., and Perlmutter, R. M. (1992) Defective T cell receptor signaling in mice lacking the thymic isoform of p59 fyn . Cell 73, 751-763.

Aroian, R. V., Koga. M., Mendel, J. E., Ohshima. Y. and Sternberg, P. W. (1990). The let-23 gene necessary for Caenorhabditis elegans vulval induction encodes a tyrosine kinase of the EGF receptor subfamily. Nature 348, 693-699.

Ashburner, M. (1989). Drosophila: A Laboratory Manual (Cold Spring Harbor, New York: Cold Spring Harbor Laboratory Press)

Basler, K., and Hafen, E. (1988). Control of photoreceptor cell fate by the sevenless protein requires a functional tyrosine kinase domain. Cell 54, 299-312.

Basler, K., Christen, B., and Hafen, E. (1991). Ligand-independent activation of the sevenless receptor tyrosine kinase changes the fate of cells in the developing Drosophila eye. Cell 64, 1069-1082.

Beitel, G. J., Clark, S. G., and Horvitz, H. R. (1990). Caenorhabditis elegans ras gene let- 60 acts as a switch in the pathway of vulval induction. Nature 348, 503-509.

Booker, G. W.. Breeze, A. L., Downing, A. K., Panayotou, G., Gout, I, Waterfield, M. D., and Campbell, I. D. (1992). Structure of an SH2 domain of the p65a subunit of phosphatidylinositol-3-OH kinase. Nature 358, 684-687.

Bourne, H. R., Sanders, D.A., and McCormick, F. (1991). The GTPase superfamily: conserved structure and molecular mechanism. Nature 349. 117-127

Bowtell, D., Fu, P., Simon, M.. and Senlor. P. (1992). Identification of murine homoloys of the Drosophila Son of sevenless gene: potential activators of ras. Proc. Natl. Acad. Ski. USA 89, 6511-6515.

Cantley, L. C., Auger, K. R., Carpenter, C., Duckworth, B., Graziani, A., Kapeller, R., and Soltoff, S. (1991). Oncogenes and signal transduction. Cell 64, 281-302.

Cicchetti, P., Mayer, B. J., Thiel, G., and Baltimore, D. (1992). Identification of a protein that binds to the $\mathrm{SH} 3$ region of $\mathrm{Abl}$ and is similar to Bcr and GAP-rho. Science 257, 803-806.

Clark. S. G., Stern, M. J., and Horvitz, H. R. (1992). C. elegans cellsignalling gene sem-5 encodes a protein with $\mathrm{SH} 2$ and $\mathrm{SH} 3$ domains. Nature 356, 340-344.

de Vries-Smits, A. M. M., Burgering. 8. M. T., Leevers. S. J., Marshall, C. J., and Bos, J. L. (1992). Involvement of p21ras in activation of intracellular signal-regulated kinase 2. Nature 357, 602-604.

Dickson, S., and Hafen, E. (1992). Genetic.dissection of eye development in Drosophiia. In The Development of Drosophila, A. Martinez-Arias and M. Bate, eds. (Cold Spring Harbor, New York: Cold Spring Harbor Laboratory Press).

Dickson, B., Sprenger, F., and Hafen, E. (1992a). Prepattern in the developing Drosophila eye revealed by an activated torso-sevenless chimeric receptor. Genes Dev. 6, 2327-2339.

Dickson, B., Sprenger, F., Morrison, D., and Hafen, E. (1992b). Raf functions downstream of Ras1 in the Sevenless signal transduction pathway. Nature 360, 600-603.

Doyle, H. J., and Bishop, J. M. (1993). Torso, a receptor tyrosine kinase required for embryonic pattern formation, shares substrates with the Sevenless and EGF-R pathways in Drosophiia. Genes Dev., in press.

Eck, M., Shoelson, S. E., and Harrison, S. C. (1993). Recognition of a high-affinity phosphotyrosyl peptide by the Src homology-2 domain of p56 ${ }^{\text {lck }}$, Nature $362,87-91$.

Gaul, U., Mardon, G., and Rubin, G. M. (1992). A putative Ras GTPase activating protein acts as a negative regulator of signaling by the sevenless receptor tyrosine kinase. Cell 68, 1007-1019. 
Gibbs, J. B., Marshall, M. S., Scolnick, E. M., Dixon, R. A. F., and Vogel, U. S. (1 990). Modulation of guanine nucleotides bound to Ras in NIH3T3 cells by oncogenes, growth factors, and the GTPase activating protein (GAP). J. Biol. Chem. 265, 20437-20442.

Greenwald, I., and Rubin, G. M. (1992). Making a difference: the role of cell-cell interactions in establishing separate identities for equivalent cells. Cell 68, 271-281.

Hafen, E., Basler, K., Edstroem, J. E., and Rubin, G. M. (1987). sevenless, a cell-specific homeotic gene of Drosophiia, encodes a putative transmembrane receptor with a tyrosine kinase domain. Science 236, 55-63.

Hagag, N., Halegona, S., and Viola, M. (1986). Inhibition of growth factor-induced differentiation of PC12 cells by microinjection of antibody to ras p2l. Nature 379, 680-682.

Han, M., and Sternberg, P. W. (1990) tet-613, a gene that specifies cell fates during $C$. elegans vulval induction, encodes a ras protein. Cell $63,921-931$.

Honegger, A. M., Kris, R. M., Ullrich, A,, and Schlessinger, J. (1989). Evidence that autophosphorylation of solubilized receptors for epidermal growth factor is mediated by intermolecular crossphosphorylation. Proc. Natl. Acad. Sci. USA 96, 925-929.

Horvitz, H. R.. and Sternberg. P. W. (1991). Multiple Intercellular signaling systems control the development of the Caenorhabditis elegans vulva. Nature 357, 535-54 1.

Hunter, T., and Cooper, T. (1985). Protein-tyrosine kinases. Annu. Rev. Biochem. 54, 897-930.

Klemenz, R., Weber, U., and Gehring, W. J. (1987). The while gene as a marker in a new P-element vector for gene transfer in Drosophila. Nucl. Acids Res. 15, 3947-3959.

Koch, C. A., Anderson, D., Moran, M. F., Ellis, C., and Pawson, T. (1991). SH2 and SH3 domains: elements that control interactrons of cytoplasmic signaling proteins. Science 252 , 668-674.

Konopka, J. B., Watanabe, S. M., and Witt, O. N. (1984). An alteration of the human c-abl-protein in K562 leukemia cells unmasks associated tyrosine kinase activity. Cell 37, 1035-1042.

Lehrnann, J. M., Reithrnuller, G., and Johnson, J. P. (1990). Nck, a melanoma cDNA encoding a cytoplasmic protern consisting of the Src homology units SH2 and SH3. Nucl. Acids Res. 18, 1048. -

Lowenstein, E. J., Daly, R. J., Batzer. A. G., Li, W.. Margolis, B., Lammers, R., Ullrich, A,, Skolnik, E. Y., Bar-Sagi, D., and Schlessinger, J. (1992). The $\mathrm{SH} 2$ and $\mathrm{SH} 3$ domain-containing protein GRB2 links receptor tyrosine kinases to ras signaling. Cell 70, 431442.

Marengere, L. E. M., and Pawson, T. (1992). Identification of residues in GAP SH2 domains that control binding to tyrosine phosphorylated growth factor receptors and p62. J. Biol. Chem. 267, 22779-22786.

Margolis, B., Li, N., Koch, A., Mohamaddi, M., Hurwitz. D. R., Zilberstein, A., Ullrich, A., Pawson, T.. and Schlessinger. J. (1990). The tyrosine phosphorylated carboxyterminus of the EGF receptor is a binding site of GAP and PLC-y. EMBO J. 9, 4375-4380.

Margolis, B., Silvennoinen, O., Comoglio, F., Roonprapunt, C., Skolnik. E., Ullrich, A.. and Schlessinger, J. (1992). High-efficiency expression/cloning of epidermal growth factor-receptor-binding proteins with Src homology 2 domains. Proc. Natl. Acad. Sci. USA 89. 8894-8898. Mayer, B. J., Hamaguchi, M., and Hanafusa, H. (1988). A novel viral oncogene with structural similarity to phospholipase C. Nature 332, 272-275.

Medema, R. H., de Vries-Smits, A. M. M., van der Zon, G. C. M., Maassen, J. A., and Bos, J. L. (1993). Ras activation by insulin and epidermal growth factor through enhanced exchange of guanine nucleotides on p21 $1^{\text {ras }}$. Mol. Cell. Biol. 13, 155-162.

Mohammadi, M., Dionne, C. A., Li, W., Li, N., Spivak, T., Honegger, A. M., Jaye, M., and Schlessinger, J. (1992). Point mutation in FGF receptor eliminates phosphatidylinositol hydrolysis without affecting mitogenesis. Nature 358, 681-684.
Mulcahy, L. S., Smith, M. R., and Stacey, D. W. (1985). Requirement for ras proto-oncogene function during serum-stimulated growth of $\mathrm{NIH}$ 3 T3 cells. Nature 313, 241-248.

Musacchio, A., Gibson, T., Lehto, V.-P., and Saraste, M. (1992a). SH3an abundant protein domain in search of afunction. FEBS Lett. 307, 55-61.

Musacchio, A., Noble, M., Wierenga, R., and Saraste, M. (1992b). Crystal structure of a src homology 3 (SH3) domain. Nature 359,851 855.

Overduin, M., Rios, C. B., Mayer, B. J., Baltimore, D.. and Cowburn, D. (1992). Three-dimensional solution structure of the src homology 2 domain of c-abl. Cell 70, 697-704.

Pawson, T., and Bernstein. A. (1990). Receptor tyrosine kinases: genetic evidence for their role in Drosophila and mouse development. Trends Genet. 6, 350-356.

Pawson, T., and Gish, G. D. (1992). SH2 and SH3 domains: from structure to function. Cell 77, 359-362.

Pelicci. G., Lanfrancone, L., Grignani, F., McGlade, J.. Cavallo, F., Forni. G., Nicoletti, I., Grignani, F., Pawson, T., and Pelicci, P. G. (1992). A novel transforming protein (SHC) with an $\mathrm{SH} 2$ domain is implicated in mitogenic signal transduction Cell 70, 93-104.

Peters, K. G., Marie, J., Wilson, E., Ives, H. E., Escobedo. J., del Rosario, M., Mirda, D., and Williams, L. T. (1992). Point mutations of an FGF receptor abolishes phosphatidylinositol turnover and $\mathrm{Ca} 2+$ flux but not mitogenesis. Nature 358. 678-681.

Price, J. V., Clifford, R. J., and Schupbach, T. (1989). The maternal ventralizing locus torpedo is allelic to faint litrie ball, an embryonic lethal, and encodes the Drosophila EGF receptor homolog. Cell 56, 1085-1092.

Ren. R., Mayer, B., Cicchetti, P., and Baltimore, D. (1993). Identification of a ten-amino acid proline-rich $\mathrm{SH} 3$ binding site. Science $259,1157-1161$.

Rogge, R., Cagan, R., Majumdar, A., Dulaney, T., and Banerjee, U. (1992). Neuronal development in the Drosophila retina: the sextra gene defines an inhibitory component in the developmental pathway of R7 photoreceptor cells. Proc. Natl. Acad. Sci. USA 89, 5271-5275.

Rogge, R. D., Karlovich, C. A., and Banerjee, U. (1991). Genetic dissection of a neurodevelopmental pathway: Son of sevenless functions downstream of the sevenless and EGF receptor tyrosine kinases. Cell 64, 39-48.

Rozakis-Adcock, M., McGlade, J., Mbamalu, G., Pelicci, G., Daly, R., Li, W., Batzer, A,, Pelicci, P. G., Schlessinger, J., and Pawson, T. (1992). Association of the Shc and Grb2/Sem-5 SH2-containing proteins is implicated in activation of the Ras pathway by tyrosine kinases. Nature 360, 689-692.

Satoh, T., Endo, M., Nakafuku, M., Akiyama, T., Yamamoto, T., and Kaziro, Y. (1990a). Accumulation of p21 $1^{\text {ras }}$ GTP in response to stimulation with epidermal growth factor and oncogene products with tyrosine kinase activity. Proc. Natl. Acad. Sci. USA 87, 7926-7929.

Satoh, T., Endo, K., Nakafuku, h4., Nakamura, S., and Kaziro, Y. (1990b). Platelet-derived growth factor stimulates formation of active P2 $1^{\text {ras }}$. GTP complex formation in Swiss mouse 3T3 cells. Proc. Natl. Acad. Sci. USA 87, 5993-5997.

Schejter, E. D., and Shilo, 5.-2. (1939). The Drosophila EGF receptor homolog (DER) gene is allelic to faint little ball, a locus essential for embryonic development. Cell 56, 1093-1104.

Simon, M. A.. Bowtell, D. D. L., Dodson, G. S., Laverty. T. R., and Rubin, G. M. (1991). Ras1 and a putative guanine nucleotide exchange factor perform crucial steps in signaling by the sevenless protein tyrosine kinase. Cell 67, 701-716.

Simon, M. A., Dodson, G. S., and Rubin, G. M. (1993). An SH3-SH2$\mathrm{SH} 3$ protein is required for $\mathrm{p} 21^{\text {Ras} 1}$ activation arid binds to sevenless and Sos proteins in vitro. Cell 73, this issue.

Skolnik, E. Y., Margolis, B., Mohammadi, M.,Lo wenstein, E., Fischer, R., Drepps, A., Ullrich, A., and Schlessinger, J. (1991). Cloning of PI3 kinase-associated p85 utilizing a novel method for expression/cloning of target proteins for receptor tyrosine kinases. Cell 65, 83-90. 
Smith, M. R., DeGudicibus, S. J., and Stacey. D. W. (1986). Requirements for c-ras proteins during viral oncogene transformation. Nature 320, 540-543.

Sprenger, F., arid Nusslein-Volhard. C. (1992). Torso receptor ac!ivitf is regulated by a diffusible ligand produced a: the extracellular terminal regions of the Drosophila egg. Cell 71, 987-1001.

Stahl, M. L., Ferenz, C. R., Kelleher, K. L., Kriz, R. W., and Knopf, J. (7 988). Sequence similarity of phospholipase $C$ with the non-catalvic region of src. Nature 332, 269-272.

Stein, P. L., Lee, H.-M., Rich, S., and Soriano, P. (1992). pp59 fyn mutant mice display differential signaling in thymocytes and peripheral T ceils. Cell 70, 741-750.

Strauss. D., and Weiss, A. (1932). Genetic evidence for the involvement of the Ick tyrosine kinase in signal transduction through the $T$ cell antigen receptor. Cell 70, 585-593.

Szeberenyi, J.. Cai, H., and Cooper, G. M. (1990). Effect of a dominant inhibitory Ha-ras mutatton on neuronal differentiation of $\mathrm{C} 12$ cells Mol. Cell. Biol. 10, 5324-5332.

Taulz, D., and Pfeifle, C. (1989). A non-radioactive in situ hybridization method for the localization of specific RNAs in Drosophila embryos reveals translational control of the segmentation gene hunchback Chromosome 98, 81-85.

Thornas, S. M., DeMarco, M., D'Arcangelo, G., Haiegoua, S., and Brugge, J. S. (1992). Ras is essential for nerve growth factor- and phorbol ester-induced tyrosine phosphorylation of MAP kinases. Cell 08, 1031-1040.

Tomlinson, A., and Ready, D. F. (1986). Sevenless. a cell-specific homeotic mutation of the Drosophila eye. Science 231, 400-402 Ullrich. A., and Schiessinger, J. (1990). Signal transduction by receptors with tyrosine kinase activity. Cell 61. 203-212.

Vega, Q. C., Cochet, C., Filhol, O., Chang, C.-P., Thee, S. G.: and Gill, G. N. (1992). A site of tyrosine phosphorylation in the C-terminus of the epidermal growth factor receptor is required to activate phospholipase C. Mol. Cell. Biol. 12, 128-135.

Waksman, G., Kominos, D., Robertson, S. C., Pant. N., Baltimore, D., Birge, R. B., Cowburn, D., Hanafusa, H., Mayer, B., Overduin, h4., Resh, M. D., Rios, C. B., Silverman, L., and Kuriyan, J. (1992). Crysta structure of the phosphotyrosine recognition domain (SH2) of the v-src tyrosine kinase complexed with tyrosine phosphorylated peptides. Nature 358, 646-653.

Wood, K. W., Sarnecki, C., Roberts, T. M., and Blennis, J. (1992). Ras mediates nerve growth factor receptor modulation of three signaltransducing protein kinases: MAP kinase, Rat-1, and RSK. Cell 68, 1041-1050.

Yu, H., Rosen, M. K., Shin, T. B., Seidel-Dugan, C., Brugge, J. S., and Schreiber, S. L. (1992). Solution structure of the SH3 domain of Src and identification of its ligand-binding site. Science 258, 1665-1666.

Zhang, K., Papageorge, A. G. and Lowy, D. R. (1992). Mechanistic aspects of signaling through Ras in NIH 3T3 cells Science 257, 671674.

GenBank Accession Number

The accession number for the sequence reported in this paper is L13173. 